Mark C. Genovese Grant/research support from: Abbvie, Eli Lilly and Company, EMD Merck Serono, Galapagos, Genentech/Roche, Gilead Sciences, Inc., GSK, Novartis, Pfizer Inc., RPharm, Sanofi Genzyme, Consultant of: Abbvie, Eli Lilly and Company, EMD Merck Serono, Genentech/Roche, Gilead Sciences, Inc., GSK, Novartis, RPharm, Sanofi Genzyme DOI: 10.1136/annrheumdis-2020-eular.2237

\begin{tabular}{|l|l}
\hline THU0205 & RESPONSE TO SMALL MOLECULES IS MOSTLY \\
DRIVEN BY PATIENT GLOBAL ASSESSMENT OF \\
DISEASE: A REAL WORLD OBSERVATION
\end{tabular}

C. Joseph ${ }^{1}$, S. M. Bilgrami ${ }^{2}$, L. Ottewell ${ }^{2}$, L. Gray ${ }^{2}$, W. Mitchell ${ }^{2}$, F. Wood ${ }^{2}$, M. Massarotti ${ }^{2}$, M. Bukhari ${ }^{1,2},{ }^{1}$ Lancaster Univeristy, Lancaster, United Kingdom; ${ }^{2}$ University Hospitals of Morecambe Bay NHS Foundation Trust, Lancaster, United Kingdom

Background: Two Small molecules (Tofacitinib and Baricitinib) have been licensed in the UK for the use in rheumatoid arthritis. Their licensing came from several studies that showed good efficacy with baricitinib (1) study showing superior efficacy to adalimumab and tofacitinib showing non inferiority to TNF drugs (2). The response has also been shown in patient reported outcomes (find reference). Response when measure using the DAS score has two relatively subjective components (tender joints and patient global assessment) and two relatively objective components (Swollen joints and inflammatory markers)

Objectives: To determine in a real world setting if the response to small molecules is mostly due to a drop in subjective or objective components of the DAS score

Methods: A retrospective chart review was done on all new starters on small molecules in a district hospital in the North of England. Data were collected at baseline, three months and six months from October 2018 to date. Drop in the components of the DAS28 score was calculated and overall drop in DAS28 was modelled as the explanatory variable using linear regression modelling. This was the done Adjusting for age gender and duration of disease. Sensitivity of the model was examined using a logistic model of EULAR moderate/good response and using adjusted $R$ squared estimates for linear model of improvement of the DAS28 score.

Results: 76 patients were included in the analysis from 85 starters on small molecules.61 $(71.8 \%)$ were on baricitinib and the baseline median DAS28 score was .5.97 (IQR 5.35,6.55)The median drop at three months in the DAS28 score was 2.42 (IQR 1.33,3.31). and at six months was 2.77 (IQR $2.01,3.83)$. There was numerical relative increased efficacy of baricitinib but this was not statistically significant (DAS drop at three months 2.54 IQR $1.73,3.09$ vs 2.12 IQR $1.51,3.5$ ). The relative contribution of the individual components of the DAS score to the drop ae in DAS are shown in table 1 below. Sensitivity analysis looking at predictors of a DAS drop of $>0.6$ confirmed this finding.

Table 1. Results of the adjusted linear regression models.

Component of DAS dropping at three Adjusted R squared at 3 months Adjusted R squared months

at six months

\begin{tabular}{lll}
\hline Swollen Joints & 0.12 & 0.05 \\
Tender Joints & 0.28 & 0.18 \\
Patient global assessment & 0.31 & 0.48 \\
Erythrocyte sedimentation rate & 0.04 & 0.17
\end{tabular}

Conclusion: In this real world observational study, there was a good response to both small molecules with numerical better response to baricitinib. Tender joint count and patient global response accounted for more of the drop in DAS28 than swollen joints and inflammatory markers. At six months the biggest contributor to response was patient global assessment. This shows that JAK inhibitors might mediate their response initially mostly through pain modulation then by inflammation as exposure to drug continues.

References:

[1] N Engl J Med. 2017 Feb 16;376(7):652-662

[2] N Engl J Med. 2014 Jun 19;370(25):2377-86

Disclosure of Interests: : Clerin Joseph: None declared, Syed Mujtaba Bilgrami Speakers bureau: Pfizer, Lesley Ottewell: None declared, Leanne Gray: None declared, William Mitchell: None declared, Fiona Wood: None declared, Marco Massarotti: None declared, Marwan Bukhari Speakers bureau: Bristol-Myers Squib, UCB celltech, Roche/Chugai, Pfizer, Abbvie, Merck, Mennarini, Sanofiaventis, Eli-Lilly, Janssen, Amgen and Novartis.

DOI: 10.1136/annrheumdis-2020-eular.3118

\section{THU0206 \\ A VERY EARLY (7-28 DAYS) RESPONSE ON JAK INHIBITOR TOFACITINIB IN PATIENTS WITH ACTIVE RHEUMATOID ARTHRITIS: EFFECT ON PAIN AND CENTRAL SENSITIZATION.}

A. Karateev ${ }^{1}$, E. Filatova ${ }^{1}$, E. Pogozheva ${ }^{1}$, V. Amirdzhanova ${ }^{1}$, E. Nasonov ${ }^{1}$,

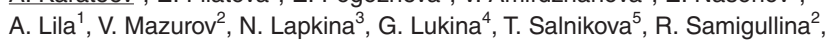
D. Chakieva ${ }^{2}$, I. Marusenko ${ }^{6}$, O. Semagina ${ }^{7}$, M. Semchenkova ${ }^{8} .{ }^{1}$ Nasonova Research Institute of Rheumatology, Moscow, Russian Federation; ${ }^{2}$ Mechnikov North-Western State Medical University, St-Petersburg, Russian Federation ${ }^{3}$ Yaroslavl State Medical University, Yaroslavl, Russian Federation; ${ }^{4}$ Moscow Clinical Scientific and Practical Centre named after Loginov AS, Moscow, Russian Federation; ${ }^{5}$ Regional Clinical Hospital, Tula, Tula, Russian Federation; ${ }^{6}$ Petrozavodsk State University, Petrozavodsk, Russian Federation; ${ }^{7}$ Regional Clinical Hospital, Samara, Samara, Russian Federation; ${ }^{8}$ Smolensk State Medical University, Smolensk, Russian Federation

Background: The presence of central sensitization (CS) significantly burdens the course of rheumatoid arthritis (RA). JAK inhibitors block intracellular signal pathways including the ones responsible for synthesis of mediators and cytokines causing pain and CS. The application of JAK inhibitors is supposed to relieve pain and reduce CS severity promptly.

Objectives: To evaluate JAK inhibitor effect on pain and signs of CS in patients with active RA 7 and 28 days after the start of therapy.

Methods: Study group included 39 patients with RA, their age was $50.9 \pm 11.1$, $79.5 \%$ of women, $89.7 \%$ of RF "+", DAS28 $5.8 \pm 0.6$, receiving DMARDs (methotrexate $82.0 \%$ and leflunomide $18.0 \%$ ), who were administered with tofacitinib $5 \mathrm{mg} 2$ times a day due to inefficiency or intolerance of genetically engineered biological drugs. There were assessed the pain severity using Brief pain inventory (BPI) questionnaire, the presence of neuropathic pain component (NPC) using PainDETECT questionnaire and signs of CS using Central Sensitisation Inventory (CSI) questionnaire at early time after tofacitinib administration.

Results: Patients initially experienced a severe pain $-5.72 \pm 2.21$ according to the visual analogue scale (VAS), $53.8 \%$ had signs of central sensitization (CSI $\geq 40$ ), $17.9 \%$ had NPC (PainDETECT $\geq 18$ ). 7 days after tofacitinib intake there was statistically reliable reduction of pain severity - up to $4.37 \pm 2.2(p=0.01)$, pain decrease of $29.4 \pm 17.9 \%$ (BPI), NCP - PainDETECT from $12.9 \pm 5.5$ to $10.6 \pm 5.6 \quad(p=0.047)$ and CS $-C S I$ from $43.1 \pm 12.8$ to $35.9 \pm 11.2(p=0.01)$. The effect had increased after 28 days: pain level (VAS) was $2.84 \pm 1.57(p=0.000)$, pain decrease of $43.6 \pm 29.6 \%$ (BPI), PainDETECT 29.8 $\pm 12.4(\mathrm{p}=0.000), \mathrm{CSI} 26.4 \pm 13.9(\mathrm{p}=0.000)$.

During this period there were no serious adverse reactions.

Conclusion: The application of JAK inhibitor tofacitinib allows to reach a fast analgesic effect, also due to impact on CS and NCP.

Source: National Registry patients with RA

Disclosure of Interests: : Andrey Karateev: None declared, Ekaterina Filatova: None declared, Elena Pogozheva: None declared, Vera Amirdzhanova: None declared, Evgeny Nasonov: None declared, Alexander Lila: None declared, V Mazurov: None declared, N Lapkina: None declared, Galina Lukina Speakers bureau: Novartis, Pfizer, UCB, Abbvie, Biocad, MSD, Roche, Tatiana Salnikova: None declared, Ruzana Samigullina: None declared, Diana Chakieva: None declared, Irina Marusenko: None declared, Olga Semagina: None declared, Marina Semchenkova: None declared DOI: 10.1136/annrheumdis-2020-eular.4029

\section{THU0207 \\ SUSTAINABILITY OF RESPONSE TO UPADACITINIB AS MONOTHERAPY OR IN COMBINATION AMONG PATIENTS WITH RHEUMATOID ARTHRITIS AND PRIOR INADEQUATE RESPONSE TO CONVENTIONAL SYNTHETIC DMARDS}

A. Kavanaugh ${ }^{1}$, M. H. Buch ${ }^{2}$, B. Combe ${ }^{3}$, L. Bessette ${ }^{4}$, I. H. Song ${ }^{5}$, Y. Song ${ }^{5}$, J. Suboticki ${ }^{5}$, P. Nash ${ }^{6} .^{1}$ University of California San Diego, San Diego, United States of America; ${ }^{2}$ University of Manchester \& NIHR Manchester Biomedical Research Centre, Manchester, United Kingdom; ${ }^{3}$ Lapeyronie Hospital, Montpellier University, Montpellier, France; ${ }^{4}$ Université Laval, Centre Hospitalier de l'Université Laval, Quebec, Canada; ${ }^{5}$ AbbVie Inc., North Chicago, United States of America; ${ }^{6}$ School of Medicine, Griffith University, Brisbane, Australia

Background: The primary treatment goal for patients (pts) with rheumatoid arthritis (RA) is a state of sustained clinical remission (REM) or low disease activity (LDA). ${ }^{1,2}$

Objectives: To assess the long-term sustainability of responses to upadacitinib (UPA), a JAK inhibitor, with or without background csDMARD(s) in pts with RA. Methods: Data are from two phase 3 randomized, controlled trials of UPA in RA pts with roughly similar baseline disease characteristics: SELECT-NEXT enrolled pts with an inadequate response (IR) to $\operatorname{csDMARD}(\mathrm{s})$ on background stable csDMARD(s) receiving UPA $15 \mathrm{mg}$ or $30 \mathrm{mg}$ once daily or placebo for 12 weeks (wks); 